\title{
PEER GROUP EFFECTS IN APPLIED
}

GENERAL EQUILIBRIUM

\section{by}

Elizabeth M. Caucutt

Discussion Paper No. 293, November 1996

Center for Economic Research

Department of Economics

University of Minnesota

Minneapolis, MN 55455 


\title{
Peer Group Effects in Applied General Equilibrium
}

\author{
Elizabeth M. Caucutt* \\ University of Minnesota
}

November 14, 1996

\begin{abstract}
In this paper, I analyze private school formation and composition, when a student's educational achievement depends upon the student's type and the school's peer group and per student expenditures. I develop applied general equilibrium techniques to find equilibrium consumption and schooling structure, in the presence of peer group effects. I find that, depending upon the specification of the technology which converts these inputs into educational achievement, a variety of outcomes can arise in equilibrium. For example there can be segregation or mixing across schools, or a combination of both. Lastly, I consider the welfare and distributional effects of three policy changes. I show that equalizing expenditures across schools reduces the range and the standard deviation of the distribution of human capital, as does forcing certain forms of integration. Both policies imply a welfare loss. I also study a voucher system. Implementing such a policy is welfare improving, given the specification of the utility function chosen here.
\end{abstract}

*Preliminary and incomplete, comments welcome, caucutt@atlas.socsci.umn.edu. I wish to thank my advisor Edward Prescott for his invaluable insight and constant encouragement. I am also grateful to Timothy Kehoe for computational advice, and Richard Rogerson, Antonio Merlo, and the participants of the University of Minnesota Applied Theory Workshop for helpful comments. 


\section{Introduction}

Statistics confirming the poor and declining performance in education in the United States abound. SAT scores fell dramatically in the 1970's. Average verbal scores fell over 50 points, while average mathematics scores fell almost 40 points. High school graduation requirements have shifted from college based to elective oriented. In 1983, remedial mathematics courses in public four year colleges constituted one-quarter of all math classes taught in those institutions. American students are continually outperformed internationally. According to a recent Department of Education study, almost half of all adult Americans are functionally illiterate.

Given this "crisis" in education, it's hardly surprising that numerous educational reforms have been proposed. Some have suggested shifting from community based funding to more centralized and egalitarian state based funding at a level considerably in excess of that currently spent in poorer districts. Many states have moved in this direction. Others have proposed reforms that are almost diametrically opposite. Several states are considering enacting or have enacted educational voucher plans, which give students money to attend private schools.

In order to evaluate these proposals, a framework is needed which incorporates the factors important to educational outcomes. Along with family background and educational expenditure, many empirical studies have also found the peer group significant to educational achievement. However, peer group effects have largely been ignored in studies that predict the consequences of alternative educational reforms. This neglect is primarily due to the difficulties that surround modeling the peer group, and not to a lack of interest or the view it lacks importance. Consider a change in educational policy, for example adopting a voucher system. Such a switch would not only affect educational expenditures, but also the school 
a student chooses to attend, and hence a school's peer group. Therefore, it is essential to have a theory that endogenizes school formation, in order to understand the consequences of alternative educational proposals.

In this paper, I analyze school formation and composition, when an individual's educational achievement depends upon his or her school's peer group and educational expenditures, and own type. I find that, depending upon the specification of the technology, which converts these inputs into educational achievement, a variety of outcomes can arise in equilibrium. For example there can be segregation or mixing across schools, or a combination of both in equilibrium.

There is a rich empirical literature that presents some strong evidence that the peer group is important to educational achievement. The principle finding of the 1966 Coleman Report, Equality of Educational Opportunity, is that a student's educational achievement is strongly and positively related to the educational background and aspirations of his or her classmates. In that exhaustive study, in which almost 20,000 school teachers distributed surveys in their classrooms, this relationship is found to be much stronger for disadvantaged students. In other words, a disadvantaged student benefits more from an increase in the ability of his or her peer group than does an advantaged student. Summers and Wolfe (1976), use data from the classroom level. They conclude that the peer group effect plays a significant role in educational outcomes. Using Canadian data, Henderson, Mieskowski, and Sauvageau (1978) also find strong evidence that the peer group is an important input in the educational process. But, they conclude that the effect the peer group has on educational achievement is similar across students of differing ability. Strong students gain from an increase in the quality of the average student in the class, as do weak students.

The theoretical literature on peer group effects is sparse. Epple and Romano (1993) construct a static model with students differing over ability and income. They constrain the 
number of schools operating in equilibrium, and do not include educational expenditures in the human capital production function. They find that under a voucher system the achievement gains of those who switch from the public schools to a private school, and hence a better peer group, are great, while the losses of those left behind are small. However, the number of students falling into the latter category is much greater. Benabou (1996) considers the effects of communities stratifying or integrating over individual types, when there are community complementarities in education and global complementarities in production. However, when studying the effects of variations in education finance, the only community level complementarity that he considers is a Tiebout type pecuniary spill over. Community composition is exogenous in his model. de Bartalome (1990) constructs a model of school districts and schools with peer group effects, and shows that there exists an inefficient equilibrium with heterogeneous schools. This inefficiency arises because the school system is public, implying that the peer group externality cannot be priced. Consequently, when an individual migrates, the social loss or gain includes the effect the migration has on the relative peer groups, but the individual simply takes into account the private loss or gain. The model has only two types of individuals.

The principle contribution of this paper is technical. I develop applied general equilibrium methods to find equilibrium consumption and schooling structure, in the presence of peer group effects. The framework used here is general equilibrium with clubs, and is based upon Cole and Prescott (1996). It has three key features. First schools have the power to price discriminate given a student's type. This allows schools to charge tuition based upon a student's ability. Second, there is a randomizing mechanism that results in convex preferences. With convex preferences attention can be, and is, restricted to type identical allocations. Third, a student's educational achievement depends not only upon own type, but also upon the the school's student body composition and per student expenditure. 
Finding an equilibrium in this framework is a difficult problem. Standard computational methods are not always successful, due to the effects of the peer group and the linearity of the utility function over schooling. Because of the randomizing mechanism, an excess demand method is not a suitable approach in this environment. An alternative is to find a pareto optimal allocation that can be supported as a competitive equilibrium with no transfers. In this paper I investigate two such approaches. The first, a standard Negishi method, is based on a mapping from the set of individual weights on the utilities of individual types to the set of transfers that support the corresponding pareto optimal allocations as competitive equilibria with transfers. The second method is a modified Mas-Colell approach. I create a mapping from the set of relative individual utilities over schooling to the set of transfers that support the corresponding pareto optimal allocations as competitive equilibria with transfers. Given the mapping, a competitive equilibrium is then found by searching over the domain to find a point where the associated transfers are zero. The corresponding pareto optimal allocation and price system is a competitive equilibrium.

Due to the linearity of utility over schooling in this environment, both the Negishi and the modified Mas-Colell mappings are correspondences. This complicates the process of searching for a competitive equilibrium. If the competitive equilibrium falls within a multivalued region of the correspondence, standard Newton methods will fail to converge. Therefore, a more general algorithm that can deal with correspondences is needed. The method used here is based on Scarf (1973), and is applied to the Negishi mapping discussed earlier. Given a finite grid of points on the simplex of weights on the utilities of individual types, the algorithm starts with a set of these points and determines whether an approximate competitive equilibrium is a convex combination of this set of points. If not, one point in the set is removed and another nearby point is brought into the set. The process continues until an approximate competitive equilibrium is found. The key to this algorithm is that it 
cannot cycle. This combined with the fact that the grid is finite, implies that the process terminates with an approximate competitive equilibrium in a finite number of steps.

Examples given in Section 4, illustrate the richness of this environment. Many different types of schools can be operating in equilibrium. Schools not only differ on expenditure levels, but also on student body composition. The framework used here is general enough to incorporate various interpretations of the peer group, and how it might affect educational outcomes. The kinds of mixing and the levels of expenditure are shown to be sensitive to how peer group effects are specified in the human capital production function.

In Section 5, I consider how changes in educational policy affect efficiency and next period's distribution of human capital. The first two policy exercises entail restricting the possible school types in some form. In the first exercise, all schools are constrained to spend the same amount per pupil. Many people feel that if expenditures are equalized across schools, educational outcomes will be equalized as well. If the peer group effect matters in educational achievement, then this is also an instrument that can be used in equalizing outcomes. In the second exercise, not only are expenditures constrained, but some forms of integration (student body composition) are required. Both policies entail a welfare loss, but also a gain through the reduction of the standard deviation and the range of next period's distribution of human capital. The third exercise investigates the ramifications of a voucher system. A parent's income is taxed proportionally and refunded in the form of a lump sum voucher, which must be spent on education. Given the specification of the utility function chosen here, this policy is welfare improving. Although the range of the distribution of human capital falls, the standard deviation of the distribution rises.

In future work, I will use modifications of techniques developed here to, more seriously, explore the effects of various educational policies on student body composition and per student expenditures. As is shown in Section 5, changes in student body makeup and 
expenditure levels can have welfare and distributional ramifications. I will investigate the policy exercises of Section 5 further, by increasing the number of types of students and by calibrating the model. I also plan to consider extensions of these policies.

The next section develops the basic structure of this environment. In Section 3 , the computational methodologies considered and those used to find the equilibrium are outlined. Section 4 contains some examples. Policy exercises are summarized in Section 5, and Section 6 concludes.

\section{Basic Structure}

The purpose of this section is to specify my model of endogenous school formation. The key feature of the model is the technologies available to groups of individuals to jointly produce human capital. The human capital that an individual acquires depends upon three factors. First, it depends upon the individual's characteristics, including family background and innate ability to learn. These characteristics are referred to as an individual's type. Second, the human capital acquired by the student depends upon the per student input of resources, or expenditures. Lastly, the human capital obtained be the student depends upon the relative numbers of the various types of students attending his or her school, or student body composition. This is the peer group. Thus a school type is characterized by its per student expenditures and its student body composition.

- Because it simplifies the analysis, I can and will consider schools that have been normalized to one student, since I permit the number of schools of a given type to vary. An alternative and equivalent approach is to have one school of each type, and allow its scale to vary. This follows because schooling displays constant returns to scale in appropriately specified inputs and outputs. 
There are a finite number of school types that a child can attend. If the parent were to choose the school type his or her child attended, preferences would not be convex, since school membership would be discrete. Consequently, there could be mutually beneficial gambles, as in Rogerson (1988). Therefore, a parent instead chooses the probability his or her child attends each school type. This convexifies preferences and ensures all gains from trade are exhausted.

The purpose of this paper is to incorporate peer group effects into the process of school formation. These effects enter into the analysis through the technology. A first issue is how these effects enter the technology. As discussed in the introduction there is an empirical debate on how and when peer group effects enter the production function. A principle conclusion of the Coleman report (1966) is that a disadvantaged student's human capital depends upon his or her peer group, but they find little evidence that an advantaged student's achievement is related to his or her classmates. Henderson, Mieszkowski, and Sauvageau (1978) find that the peer group effects are similar for students of differing ability. Hence all student's human capital depends upon his or her peer group in the same manner.

The framework developed here is general enough to allow for various specifications of these peer group effects within the human capital production function. For example, following Coleman (1966), the technology could be such that advantaged students aren't affected by their peer group, while disadvantaged students are. Or, as in Henderson, Mieszkowski, and Sauvageau (1978), the peer group could affect all students in the same manner.

- A second issue is what defines the quality of the peer group. Initially I assume that the quality of the peer group, in a school, is measured solely by the mean of the inherited learning efficiency of those attending that school. This assumption can easily be relaxed to incorporate such possibilities as allowing the variance of learning efficiency within a school to matter, or defining the school's peer group by the best or the worst student. 


\subsection{The Environment}

There are $I$ types of people (parents), endowed with varying levels of learning efficiency and human capital. For simplicity, initially, a one-to-one relationship between human capital and wage is assumed. The initial endowments of human capital (or wage) and learning efficiency, are given by $h^{i}, i=1, \ldots, I$, and $a^{i}, i=1, \ldots, I$, respectively. There is a continuum of type $i$

people of measure $\lambda^{i}>0$, and $\sum_{i} \lambda^{i}=1$. A person has one child, who must attend school, where he or she accumulates human capital according to some technology. The child inherits the learning efficiency of the parent, and this information is known. A parent cares about consumption and the human capital the child receives.

There are a finite number school types. Because the choice to attend a specific school is exclusionary, in the sense that attending one school precludes a student from attending another, a randomizing mechanism is introduced to convexify the problems facing the parents. With convexity, attention can be and is restricted to type identical allocations. This is illustrated in Section 2.3. Therefore, parents randomize over the finite set of schools by choosing the probability that their child attends each school type, $s$, in order to maximize expected utility, $E\left\{u(c)+v\left(h^{\prime}\right)\right\}$.

\subsection{The Economy}

\section{Commodity Space}

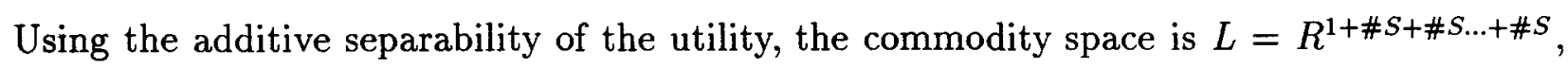
where $S$ is the set of possible schools a child can attend. An element of the commodity space is denoted by $x=\left(c, \pi^{1}, \pi^{2}, \ldots, \pi^{I}\right)$, where $c$ is personal consumption, and the $\pi^{i}$ are vectors of probabilities associated with each possible outcome in $S$. Therefore, $\pi_{s}^{1}$ refers to the probability a child of a type 1 parent attends school type $s$. The consumption possibilities 
set for type $i$ is,

$$
X^{i}=\left\{x \in L_{+}: \sum_{S} \pi^{i}=1, \pi^{j}=0, \forall j \neq i\right\}
$$

Consumption is non-negative and the probabilities, $\pi_{s}^{i}$ satisfy, $0 \leq \pi_{s}^{i} \leq 1, \forall i, s$. A type $i$ parent has $\pi^{j}=0$. For example, a type 1 parent has, $\pi_{s}^{2}=0, \forall s$.

\section{Preferences}

Utility, $U^{i}: X^{i} \rightarrow R$ is defined as,

$$
U^{i}(x)=u(c)+\sum_{s} v_{s}^{i} \pi_{s}^{i}
$$

where $u$ is strictly concave, monotone, and $u^{\prime}(c) \rightarrow \infty$ as $c \rightarrow 0$. Here, $v_{s}$ is the utility a parent receives if his or her child attends school $s$. This utility is a function of the human capital the child acquires from school s. A parent receives utility from the consumption good, and from the type of school his or her child attends. The parent's endowment is given by $\omega^{i}=\left(h^{i}, \mathbf{0}, \mathbf{0}, \ldots, \mathbf{0}\right) \in L_{+}$. Hence the parent is endowed only with units of the consumption good.

\section{Technologies}

There are a finite number of school types, $S$. Each school $s$ in $S$, is defined by the fraction of each type in attendance, $n_{s}^{i}, i=1, \ldots, I$, and its per pupil expenditures, $e_{s}$. Recall a school is normalized to a size of one student and the measure of each school type, $s$, is $z_{s}$. Therefore, the set of possible school types, $S$, is exogenous, while the measure of each school type, $z_{s}$, is endogenous. The aggregate production possibility set is then:

$$
Y=\left\{y \in L: \exists z \text { s.t. } \sum_{s} e_{s} z_{s}+y_{c} \leq 0 ; y_{s}^{i}=z_{s} n_{s}^{i}, \forall i, s\right\}
$$

Note, $\sum_{s} e_{s} z_{s}$ is the total expenditures on schooling, so $y_{c}$ is the amount of consumption good used as an input to schooling. The fraction of children of type $i$ parents in school $s$ is 
$n_{s}^{i}$ and $z_{s}$ is the measure of type $s$ schools, therefore $y_{s}^{i}$ is the mass of students, with type $i$ parents, attending school $s$.

\section{Resource Constraint}

The resource constraint is $\sum_{i} \lambda^{i}\left(x^{i}-\omega^{i}\right)=y$. This implies that $\pi_{s}^{i}=\frac{n_{s}^{i} z_{s}}{\lambda^{i}}, \forall s, i$, and $\sum_{i} \lambda^{i} c^{i}+\sum_{s} z_{s} e_{s} \leq \sum_{i} \lambda^{i} h^{i}$. The first $i \cdot s$ constraints assure that the probabilities the parent chooses match the measures the schools choose. The last constraint is the consumption resource constraint.

\subsection{Competitive Equilibrium}

\section{Prices}

The price system is $p \in L$. The value of a commodity point, $x$, is $p \cdot x$. Let $c$ be the numeraire. Therefore, prices are in terms of the consumption good. Since the output good is the numeraire, the resource input to schooling is simply referred to as per student expenditures.

\section{Definition of Equilibrium}

A type identical competitive equilibrium is a price system $p$ and an allocation $\left[y^{*},\left\{x^{i *}\right\}\right]$ such that:

1. $x^{i *}$ maximizes $U^{i}(x)$ subject to $x^{i} \in X^{i}$ and $p \cdot\left(x^{i}-\omega^{i}\right) \leq 0, i=1, \ldots I$,

2. $y^{*}$ maximizes $p \cdot y$ subject to $y \in Y$, and

3. $\sum_{i} \lambda^{i}\left(x^{i}-\omega^{i}\right)=y$. 


\section{Type Identical Allocations}

As mentioned previously, I restrict my attention to type identical allocations. If an equilibrium exists where individuals of a given type are consuming different allocations, then there is also an equilibrium where everyone of that type consumes identical allocations. These are the type identical equilibria which I consider.

Proposition 1 If there is an equilibrium with $x$ differing across individuals of the same type, then an equilibrium exists such that:

$$
x^{i}=\bar{x}^{i} \equiv \frac{1}{\lambda^{i}} \int x^{i}(j) d j, \forall i
$$

with $p$ and $y$ the same.

Proof: If $x^{i}(j) \in X^{i}, \forall j$, then by the convexity of $X, \bar{x}^{i} \in X^{i}$. Therefore, $\bar{x}$ is in the commodity space.

$$
U(x(j))=\bar{U}, \forall j . \text { By the linearity of } U, U(\bar{x})=\bar{U} \text {. Therefore, } \bar{x} \text { is yielding maximal }
$$
utility.

Since $\bar{x}$ is a convex combination, and $p$ and $y$ are the same, under $\bar{x}$ school's are still maximizing profits, the budget constraints hold, and the resource constraint is satisfied.

Therefore $\bar{x}$ along with $p$ and $y$ is a type identical competitive equilibrium.

$$
\diamond
$$

The remainder of this section contains propositions that are used in the computation. I first verify that an equilibrium exists, and then show that the Second Welfare Theorem holds. 


\section{Existence of an Equilibrium}

Proposition 2 An equilibrium allocation, $\left[y^{*},\left\{x^{i *}\right\}\right]$, and price system, $p$, exist in this environment.

Proof: If the following conditions hold, then according to McKenzie (1959), an equilibrium exists.

C1. For each $i$, the consumption set $X^{i}$ is closed, convex, and bounded.

C2. For each $i, U^{i}$ is strictly convex and continuous

C3. $Y$ is a closed convex cone.

C4. $Y \cap \Omega=\{0\}$, where $\Omega=\left\{x \in R^{m} \mid x \geq 0\right\}$.

C5. $X^{i} \cap Y$ has an interior point

C6. No consumer is satiated at $p$.

$\diamond$

\section{The Second Welfare Theorem}

Because my computational methodology is based on finding the pareto optimal allocation that can be supported as a competitive equilibrium with no transfers, it is crucial that the Second Welfare Theorem hold. I show that in this framework, there exists a price system, $p$, that supports each pareto optimal allocation as a quasi-competitive equilibrium with transfers. Once I construct a price system, I can then verify that there is a cheaper point in the consumption possibility set. This implies that the quasi-competitive equilibrium is in fact a competitive equilibrium. 
Proposition 3 There exist prices, $p$, that support each pareto optimal allocation as a quasicompetitive equilibrium with transfers (Second Welfare Theorem)

Proof: If the following conditions hold, then according to Stokey and Lucas, with Prescott (1989), p. 455, the Second Welfare Theorem holds.

C1. For each $i$, the consumption set $X^{i}$ is convex.

C2. For each $i$, if $x, x^{\prime} \in X^{i}, U^{i}(x)>U^{i}\left(x^{\prime}\right)$, and $\theta \in(0,1)$ then $U^{i}\left[\theta x+(1-\theta) x^{\prime}\right]>U^{i}\left(x^{\prime}\right)$.

C3. For each $i, U^{i}$ is continuous.

C4. The aggregate production possibility set, $Y$, is convex.

C5. The commodity space, $L$, is finite dimensional.

C6. At least one person is not satiated at the pareto optimal allocation.

C1 follows from the randomizing mechanism. C2 follows from the strict concavity of $u^{i}$. C6 follows from monotonicity of $u^{i}$.

\section{Computing an Equilibrium}

In this section I discuss the computational subtleties encountered when trying to find a competitive equilibrium in this environment. I consider the social planner's problems that weight different types of individuals differently. Solutions to these problems are pareto optimal allocations, and by the Second Welfare Theorem they can be supported as competitive equilibria 
with transfers. Any set of weights for which the transfers are zero, implies a competitive equilibrium allocation.

I construct a mapping from the set of weights on the utilities of individual types in a social planner's problem to transfers that support the corresponding pareto optimal allocations as competitive equilibria, with transfers. This is referred to as the Negishi mapping. Given a vector of weights, I begin by finding a pareto optimal allocation. This is a straightforward computation based on the weighted social planner's problem. I then construct a price system, which is used to calculate the transfers necessary to support the pareto allocation as a competitive equilibrium with transfers. This completes the mapping from the space of individual weights to the space of transfers. Unfortunately this mapping is a correspondence. Standard Newton methods applied to mappings that are correspondences sometimes fail to converge to a competitive equilibrium.

To avoid working with a correspondence, I developed a second mapping. The modified Mas-Colell is based on a mapping from the relative utility over schooling space to the transfer space. First, given a vector of relative utilities over schooling, I find an associated pareto optimal allocation. Second, I calculate the transfers required to support this pareto optimal allocation as a competitive equilibrium. This is accomplished by constructing a supporting price vector. Therefore, there is a mapping from the relative utility over schooling space to the transfer space. However, the modified Mas-Colell mapping is also a correspondence. Problems, similar to those encountered with the Negishi mapping, arise when using standard Newton methods to find a competitive equilibrium.

In order to consistently find a competitive equilibrium, a method of search that can be applied to correspondences is needed. I return to the Negishi mapping, because the space of weights on the utilities of individual types can be thought of as a simplex, and I use a grid search algorithm based on Scarf (1973) to find a competitive equilibrium. 
In the remainder of this section I outline how each mapping is constructed (the details of the modified Mas-Colell mapping are contained in the appendix). I then discuss what causes these mappings to be correspondences, and I show how and when standard Newton methods applied to these mappings can breakdown and fail to converge to a competitive equilibrium. Lastly, I illustrate my methodology for circumventing these problems by using Scarf's algorithm.

\subsection{The Negishi Mapping}

The Negishi method of finding the competitive equilibrium is based on a mapping from a vector of individual weights in a social planner's problem to a vector of transfers that support the corresponding pareto optimal allocations as competitive equilibria. Creating this mapping entails finding a pareto optimal allocation that corresponds to a given vector of weights, and then constructing the transfers that would support this allocation as a competitive equilibrium.

To find a competitive equilibrium, I make use of the $\theta$-weighted planner's problem. I first show that a solution to the $\theta$-planner's problem exists. I then prove that the solutions to the planner's problem are indeed the set of $\theta$-pareto optimal allocations. I next make use of the Second Welfare Theorem to show that for each $\theta$-pareto optimal allocation there exists a set of prices that support it as a competitive equilibrium with transfers. Given the $\theta$-allocation, I establish a procedure for finding a set of equilibrium prices. Given these prices, when the transfers are zero, the corresponding pareto allocation and prices constitute a competitive equilibrium. To find a competitive equilibrium, I search over $\theta$, until I find a $\theta$-allocation where transfers are zero. 


\section{Finding a pareto optimal allocation}

The planner's problem:

$$
\begin{array}{ll}
\max _{z, c} & \sum_{i} \theta^{i} \lambda^{i}\left[u\left(c^{i}\right)+\sum_{s} v_{s}^{i} n_{s}^{i} z_{s} / \lambda^{i}\right] \\
\text { s.t. } & \sum_{i} \lambda^{i} c^{i}+\sum_{s} e_{s} z_{s}=\sum_{i} \lambda^{i} h^{i}, \\
& \sum_{s} n_{s}^{i} z_{s}=\lambda^{i}, \quad \forall i .
\end{array}
$$

Here the $\theta^{i}$ weights are nonnegative and sum to one. First, I show that a solution to the planner's problem exists for each set of weights, $\theta$. I then verify that the solutions to the planner's problem are in fact pareto optimal.

Proposition 4 As long as the constraint set is nonempty, there exists a solution $\{z(\theta), c(\theta)\}$ to the $\theta$-planner's problem.

Proof: The proposition follows from the continuity of the objective function and the compactness of the constraint set. The constraint set is compact because it is bounded,

closed, and finite dimensional. Consumption and expenditures on schooling are bounded by the resource constraint, and the probabilities are bounded by zero and one. The constraint set is closed due to the weak inequalities that define the set.

$\diamond$

Proposition 5 For each $\theta$, the solutions to the planner's problem is pareto optimal.

Proof: When all $\theta^{i}>0$ this is true. It is not so clear when one or more $\theta^{i}=0$. However, when some $\theta^{i}=0$, the $\theta$-allocation cannot be a competitive equilibrium. Everyone must do better in competitive equilibrium than in autarky. Since each type begins with a 
positive endowment, they will always be better off consuming their endowment when zero weight is placed upon them. Hence, I can ignore the case of some $\theta^{i}=0$.

To find a pareto allocation computationally, I rewrite the planner's problem by moving the consumption resource constraint into the objective. Note, $\Gamma$ is the lagrange multiplier on the consumption resource constraint.

$$
\begin{array}{cc}
\max _{z, c} \quad \sum_{i} \theta^{i} \lambda^{i} u\left(c^{i}\right)-\Gamma\left(\sum_{i} \lambda^{i}\left(c^{i}-h^{i}\right)\right)+ \\
\\
\sum_{s} z_{s}\left[\left(\sum_{i} \theta^{i} n_{s}^{i} v_{s}^{i}\right)-\Gamma e_{s}\right] \\
\text { s.t. } \quad \sum_{s} z_{s} n_{s}^{i}=\lambda^{i}, \forall i .
\end{array}
$$

The first order condition with respect to $c$ yields, $\theta^{i} \lambda^{i} u^{\prime}\left(c^{i}\right)-\Gamma \lambda^{i}=0$. Therefore, $\Gamma$ implies $c^{i}, \forall i$. So, given the $\Gamma$, the problem is linear in $z$. Consequently, given $\Gamma$, this problem can easily be solved for $z$ using linear programming techniques. The algorithm I use to find a pareto allocation given $\theta$, begins with choosing the lagrange multiplier on the consumption resource constraint, $\Gamma$. Given $\Gamma$ and $\theta$, individual consumption, $c^{i}$, immediately follows from the first order condition with respect to individual consumption. I then solve the above planner's problem for $z$ using a linear program. I next check if the resource constraint holds. If not, I adjust the lagrange multiplier, using a bisection method, and repeat the process, until the consumption resource constraint is satisfied. This allocation is a $\theta$-pareto allocation.

\section{Finding the transfers}

According to the Second Welfare Theorem, prices that support each pareto optimal allocation as a quasi-competitive equilibrium exist. It is standard to return to the consumer's problem 
to construct equilibrium prices. However, that method doesn't work in this framework because prices constructed from the consumer's problem depend upon the lagrange multiplier on the probabilities summing to one constraint. Unfortunately it is not obvious what this lagrange multiplier is. But, turning to the social planner's problem, there is an underlying relationship between the lagrange multipliers on the probability constraints in the consumer's problems, and the lagrange multipliers on the adding up constraints, $\sum_{s} z_{s} n_{s}^{i}=\lambda^{i}$, in the pareto problem. Consequently, combining the optimality conditions from the pareto problem and the consumer's problems, with zero profit conditions, yields a system of prices. The method is outlined below.

Proposition 6 Given the solution to the $\theta$-pareto problem, $\{z(\theta), c(\theta)\}$, price system,

$$
p_{s}^{i}(\theta)=\frac{\theta^{i} v_{s}^{i}-\mu^{i}(\theta)}{\theta^{i} u^{\prime}\left(x_{c}^{i}(\theta)\right)}
$$

supports $\{z(\theta), c(\theta)\}$ as a quasi-competitive equilibrium, where the $\mu^{i}$ 's are the lagrange multipliers from the $\theta$-pareto problem.

Proof: Begin by rewriting the $\theta$-pareto problem:

$$
\begin{array}{cc}
\max _{z, c} & \sum_{i} \theta^{i} \lambda^{i} u\left(c^{i}\right)-\Gamma\left(\sum_{i} \lambda^{i}\left(c^{i}-h^{i}\right)\right)+ \\
& \sum_{s} z_{s}\left[\left(\sum_{i} \theta^{i} n_{s}^{i} v_{s}^{i}\right)-\Gamma e_{s}\right] \\
\text { s.t. } & \sum_{s} z_{s} n_{s}^{i}=\lambda^{i}, \forall i .
\end{array}
$$


Note, $\Gamma$ is the lagrange multiplier on the resource constraint. If $z_{s}(\theta)>0$, the first order condition with respect to $z_{s}(\theta)>0$ is:

$$
\sum_{i} \theta n_{s}^{i} v_{s}^{i}-\Gamma(\theta) e_{s}-\sum \mu^{i} n_{s}^{i}=0
$$

If school $s$ is operated, zero profits imply $\sum n_{s}^{i} p_{s}^{i}(\theta)=e_{s}$. Substitute this into the first order condition, to get,

$$
\sum_{i} n_{s}^{i}\left[\theta^{i} v_{s}^{i}-\Gamma(\theta) p_{s}^{i}(\theta)-\mu^{i}(\theta)\right]=0
$$

From the first order conditions with respect to consumption, we know that $\Gamma(\theta)=\theta^{i} u^{\prime}\left(c^{i}\right)$. Therefore we have:

$$
\sum_{i} n_{s}^{i}\left[\theta^{i} v_{s}^{i}-\theta^{i} u^{\prime}\left(c^{i}(\theta)\right) p_{s}^{i}(\theta)-\mu^{i}(\theta)\right]=0
$$

Therefore, a candidate price system when $z_{s}(\theta)>0$, is:

$$
p_{s}^{i}(\theta)=\frac{\theta^{i} v_{s}^{i}-\mu^{i}(\theta)}{\theta^{i} u^{\prime}\left(c^{i}(\theta)\right)} .
$$

If a school is not operating, $z_{s}(\theta)=0$, and the first order condition with respect to $z_{s}(\theta)$ is:

$$
\sum_{i} \theta n_{s}^{i} v_{s}^{i}-\Gamma(\theta) e_{s}-\sum \mu^{i} n_{s}^{i} \leq 0
$$

If $z_{s}(\theta)=0$, profits of school $s$ are nonpositive,

$$
\sum n_{s}^{i} p_{s}^{i}(\theta) \leq e_{s} .
$$


Therefore, $e_{s} \geq \sum n_{s}^{i} p_{s}^{i}(\theta)$, and $e_{s} \geq \sum_{i} n_{s}^{i}\left[\theta v_{s}^{i}-\mu^{i}-\theta u^{\prime}\left(c^{i}(\theta)\right)\right]$. So a candidate price system for schools that are not operating, $z_{s}(\theta)=0$, is:

$$
p_{s}^{i}(\theta)=\frac{\theta^{i} v_{s}^{i}-\mu^{i}(\theta)}{\theta^{i} u^{\prime}\left(c^{i}(\theta)\right)},
$$

which has the same structure as the price system for operating schools.

$\diamond$

The next proposition establishes that this price system is one which supports each $\theta$-pareto optimal allocation as not only a quasi-competitive equilibrium with transfers, but as a competitive equilibrium with transfers. This is an extension to the Second Welfare Theorem discussion in Section 2.3, and is commonly referred to as the Remark.

Proposition 7 If for each person there is a point cheaper than the pareto optimal allocation, in their consumption possibility set, then the price system $p$, supports each $\theta$-pareto optimal allocation as a competitive equilibrium with transfers (Remark)

\section{Próof}

This follows from the fact that everyone will always be consuming positive amounts $c>0$, so that $c=0$ will be cheaper, holding $z_{s}$ fixed. 
Prices are easily constructed as described in proposition 6 . Transfers are then,

$$
t^{i}(\theta)=h^{i}-c^{i}(\theta)-\sum_{s} p_{s}^{i}(\theta) \frac{z_{s}(\theta) n_{s}^{i}}{\lambda^{i}}, i=1, \ldots, I
$$

\section{Finding a competitive equilibrium}

A mapping has been constructed from the space of individual weights to the space of trans-

fers. The last step of this computational procedure is to search over the space of weights for a vector of weights which results in a zero transfer vector. This vector of weights gives rise to a pareto optimal allocation that can be supported as a competitive equilibrium with no transfers. This allocation, along with the corresponding price system, is a competitive equilibrium.

\subsection{The Modified Mas-Colell Mapping}

The second mapping is a modified Mas-Colell method, which is based on a mapping from the relative utility over schooling space to the transfer space. I start in the relative utility over schooling possibility space, and create a mapping from a vector of relative utilities over schooling to a vector of transfers that support the associated pareto optimal allocations as competitive equilibria. This mapping is more involved computationally than the Negishi mapping. Given a vector of utilities over schooling, I first construct an associated pareto optimal allocation. The optimal schooling structure is found by solving the linear programming problem of minimizing total school expenditures, subject to utility and attendance constraints. The optimal consumption allocation then arises from the resulting marginal utilities over schooling. If this allocation is not feasible, I then scale the initial utility over schooling vector up or down by a constant, until the corresponding allocation is feasible. Once I have the pareto optimal allocation, I next construct a price system. Given the 
price system, I calculate the transfers which support the pareto allocation as a competitive equilibrium with transfers. The details of this mapping are discussed in appendix A.

\subsection{Complications}

Both the Negishi and the modified Mas-Colell mappings are correspondences. This can cause a standard Newton algorithm to fail to converge. If the equilibrium falls within one of the multivalued regions, difficulties arise. However, if the equilibrium falls on a section of the mapping that is a function, there is convergence.

\subsubsection{The Negishi mapping}

With the Negishi mapping the correspondence arises because for some $\theta$, the planner's problem (1) does not have a unique solution. Total consumption stays constant, and this together with the relationship between $\theta$ and individual consumption, implies that individual consumption is constant. Total resources used in schooling is also constant. However, the way in which these resources are allocated varies. This difference implies that for some $\theta$ there is a continuum of associated transfers.

Imagine a utility space as in figure 1 with two types of people. Given $\theta$, a $\theta$-pareto allocation is the point of tangency between a line with slope $\theta$, and the utility possibility frontier. Notice that the utility possibility frontier is linear between points A and B. For some $\theta$, all convex combinations of $\mathrm{A}$ and $\mathrm{B}$ are pareto optimal allocations. Suppose one of those allocations is a competitive equilibrium. As the Newton algorithm converges from the right, transfers to type 1 are negative and converging to what they are at A. Coming from the left, however, transfers to type 1 are positive and converging to their value at $B$. The algorithm will oscillate from side to side, failing to converge to the equilibrium. 


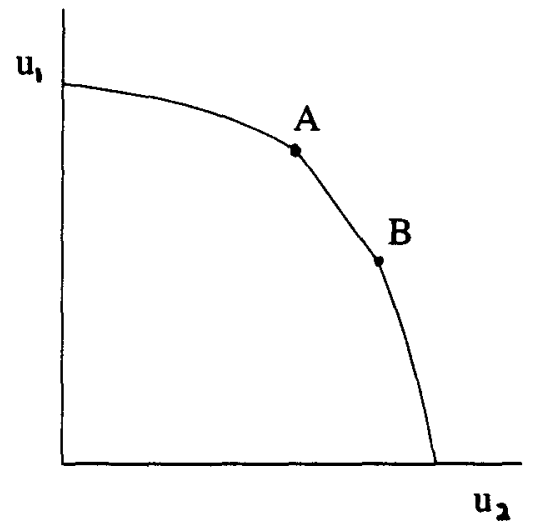

figure 1

It is important to understand when there will be convergence and when there won't be convergence. Consider figures 2 and 3 . In figure 2 , the competitive equilibrium falls within a multivalued region of the mapping, and Newton does not converge. In figure 3, the competitive equilibrium is on a section of the mapping that is a function. The Newton method will bypass the multivalued regions and converge to a competitive equilibrium. Problems would only arise if the algorithm somehow landed in one of the multivalued regions. This is virtually computationally impossible.

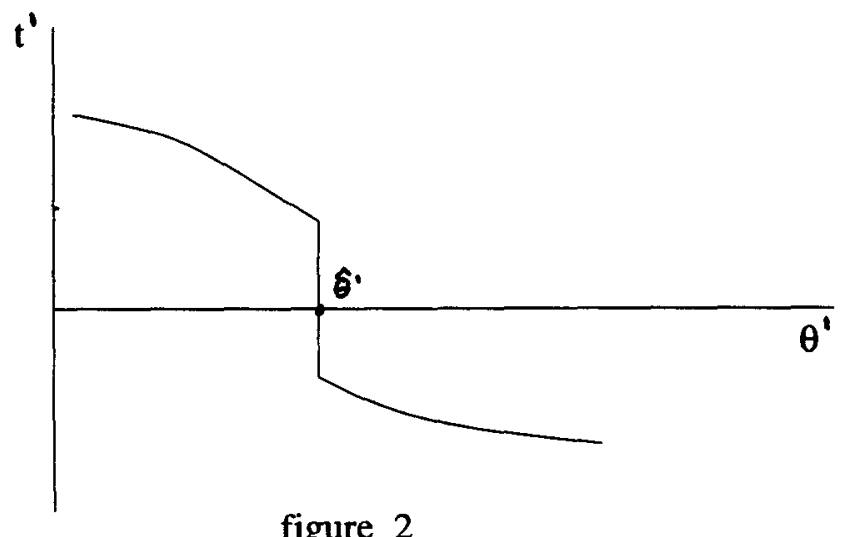




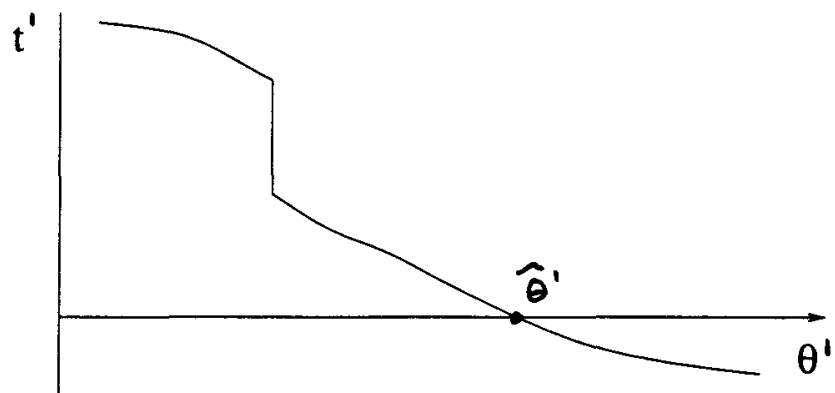

figure 3

\subsubsection{The modified Mas-Colell mapping}

Similar problems arise with the modified Mas-Colell mapping for similar reasons. Returning to figure 1, the reason for developing this approach is the apparent one to one relationship between a utility vector and a pareto allocation. Specifically, each of the pareto allocations between $\mathrm{A}$ and $\mathrm{B}$, which are all associated with one $\theta$, would be associated with a unique utility vector. Computationally, however, it is virtually impossible to create a mapping from the utility space to transfers. Given a utility vector there is no obvious way to know how much of it comes from consumption and how much is due to schooling. One could guess a vector of individual consumptions, solve a linear programming problem to construct schooling structure given the implied utility over schooling, and then check if total utility is matched. This would entail searching over an $I$ dimensional space, just to find one pareto allocation. The Newton method then repeats this calculation $I-1$ times each iteration, to pick the next vector of utility. So each iteration would consist of searching over an $I$ dimensional space $I$ times. As the number of types increases, this is clearly infeasible.

Therefore, I developed a modified Mas-Colell approach. Instead of working from the utility space, I use the utility over schooling space. Unfortunately, this does not avoid the correspondence problems encountered with the Negishi mapping. The correspondence here arises because, given $u_{s}$, there can be multiple solutions to the cost minimization problem 
(6). All of these solutions yield the same utility over schooling, and total expenditures on schooling. Therefore they also all have the same total consumption. However, the way in which consumption is allocated across individuals varies. This causes the continuum of pareto optimal allocations associated with a single $u_{s}$ vector to have different transfer vectors. Therefore the mapping from the utility over schooling space to transfers is a correspondence.

Suppose that we have two types, as in figure 4, and that point $\mathrm{A}$ is associated with a continuum of pareto allocations. Also suppose that one of those pareto allocations is a competitive equilibrium. As the Newton algorithm converges from the right, transfers to type 1 are negative and converging to the most negative transfer in A. Converging from the left, transfers to type 1 are positive and converging to the most positive transfer in $A$. The algorithm will oscillate between these two endpoints of $\mathrm{A}$, failing to converge to the equilibrium. As with the Negishi method, the Newton algorithm applied to the modified Mas-Colell mapping can converge. If the competitive equilibrium falls on a section of the mapping which is a function, Newton will converge.

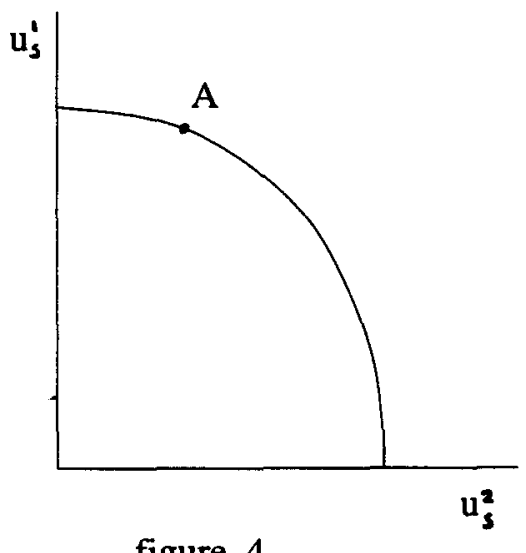




\subsection{Scarf's Algorithm}

The method I use to find a competitive equilibrium, when Newton methods fail to converge, is an algorithm based on Scarf (1973). This algorithm is general enough to incorporate mappings which are correspondences. It uses the Negishi mapping of section 3.1 , and searches over the simplex of weights for a vector of weights that gives rise to a pareto allocation that can be supported as a competitive equilibrium with no transfers. The idea is to search in such a way that only a small fraction of the grid must be considered. The algorithm starts with a subsimplex and searches by removing one vertex and replacing it with another. This process continues until an approximate competitive equilibrium is found.

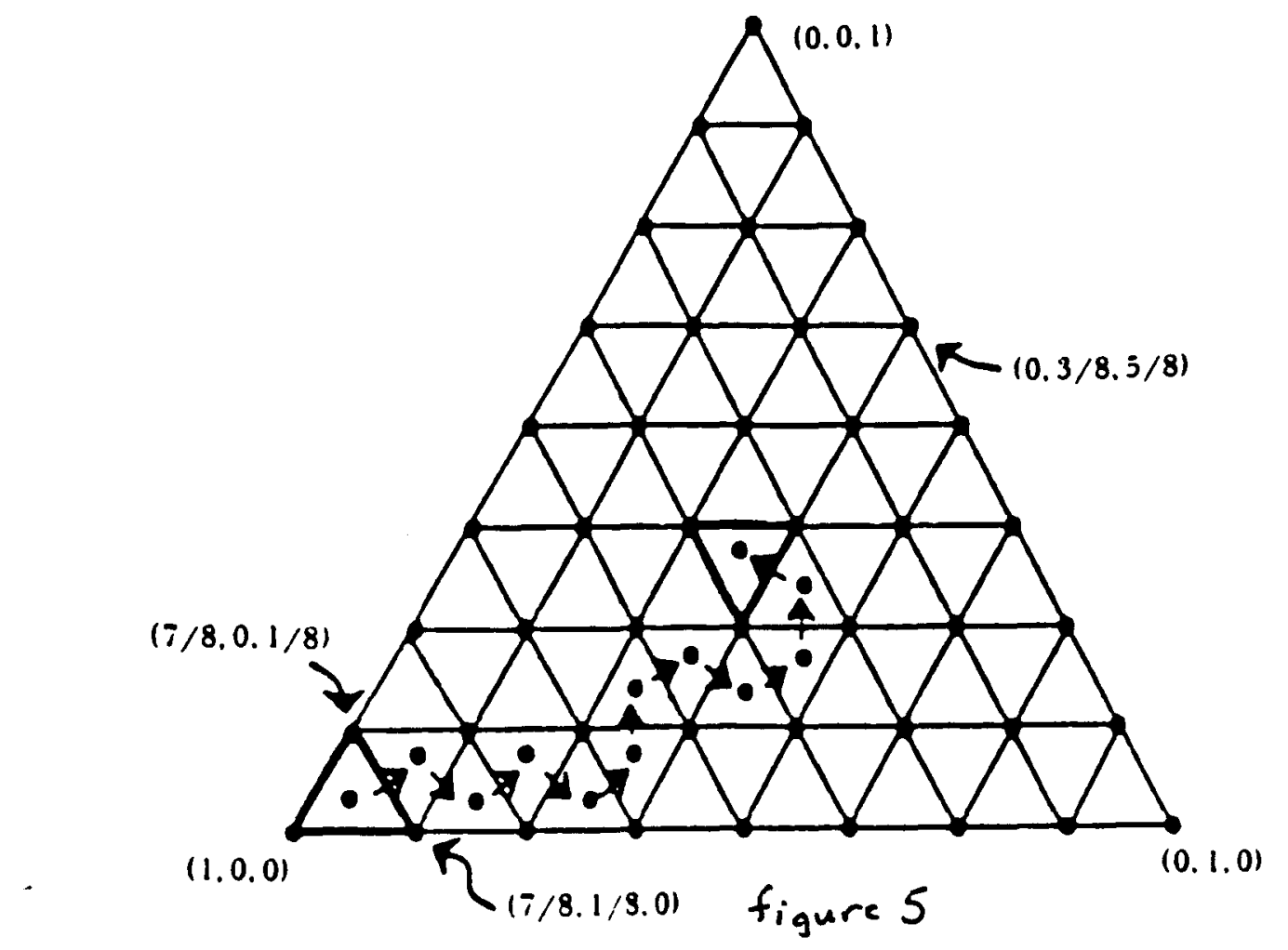

Imagine there are three types of people. The weight simplex would be as in figure 5. If the simplex is divided into subsimplices as shown, the grid is then made up of points of the form $\left(m_{1} / 8, m_{2} / 8, m_{3} / 8\right)$, where $m_{1}, m_{2}$, and $m_{3}$ are nonnegative integers that sum to 8 . There is necessarily a subsimplex where any convex combination of its vertices is an 
approximate competitive equilibrium, and Scarf's algorithm gives a method for finding this subsimplex in an efficient manner.

Each vertex in the simplex is given a vector label, $L\left(\theta^{i}\right)=t^{i}+e$, where $t^{i} \in T\left(\theta^{i}\right)$ and $e$ is a vector of ones. Here $T$ is the Negishi correspondence. Scarf's algorithm is based on the fact that there exists a subsimplex such that:

$$
\sum_{i=1}^{m} \alpha_{i}\left(t^{i}+e\right)=e
$$

If $\sum_{i} \alpha_{i}=1$, then $\sum_{i} \alpha_{i} t^{i}=0$. Therefore, any convex combination of the vertices $\theta$ is an approximate competitive equilibrium. This approximation becomes closer to the true competitive equilibrium as the grid becomes finer.

Proposition 8 If $\sum_{i=1}^{m} \alpha_{i}\left(t^{i}+e\right)=e$, then $\sum_{i} \alpha_{i}=1$

\section{Proof}

Rewrite 4 as:

$$
\alpha_{1}\left[\begin{array}{c}
t_{1}^{1} \\
\cdot \\
\cdot \\
\cdot \\
t_{m}^{1}
\end{array}\right]+\ldots+\alpha_{m}\left[\begin{array}{c}
t_{1}^{m} \\
\cdot \\
\cdot \\
\cdot \\
t_{m}^{m}
\end{array}\right]=\left(1-\sum_{i} \alpha_{i}\right)\left[\begin{array}{c}
1 \\
\cdot \\
\cdot \\
\cdot \\
1
\end{array}\right]
$$

Take the $j^{\text {th }}$ row of the above system:

$$
\sum_{i} \alpha^{i} t_{j}^{i}=1-\sum_{i} \alpha_{i}, \forall j
$$

Sum over $j$ :

$$
\sum_{i} \alpha^{i} \sum_{j} t_{j}^{i}=m\left(1-\sum_{i} \alpha_{i}\right)
$$


Since $\sum_{j} t_{j}^{i}=0$ :

$$
\sum_{i} \alpha_{i}=1
$$

It is important to understand how the algorithm moves through the simplex. As previously mentioned, every grid point in the simplex is given a label $L(\theta)$. The labels for the sides of the simplex, $\left(\theta^{1}, \ldots \theta^{m}\right)$, are as follows:

$$
\begin{array}{ccc}
\theta^{1} & \rightarrow & (1,0, \ldots, 0) \\
\theta^{2} & \rightarrow & (0,1, \ldots, 0) \\
\cdot & \cdot \\
\cdot & \cdot \\
\theta^{m} & \rightarrow & (0,0, \ldots, 1) .
\end{array}
$$

Construct a matrix $A$ containing all of the label vectors:

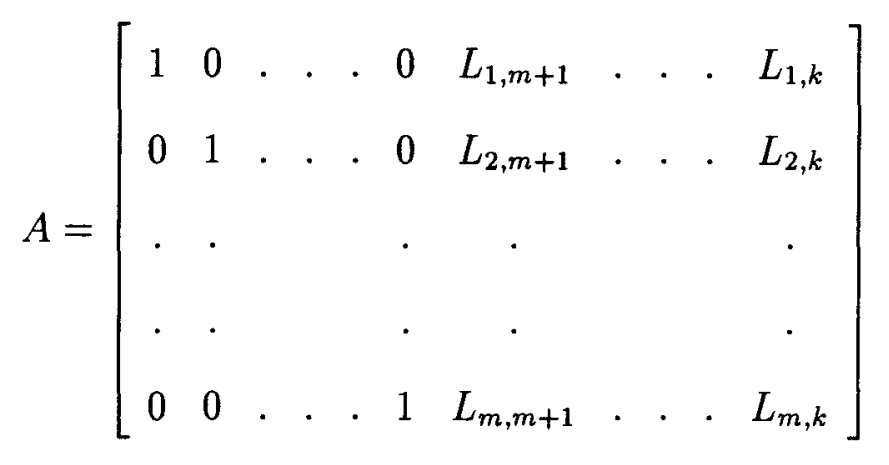

The first $m$ columns correspond to the labels for the weights on the sides of the simplex, $\left(\theta^{1}, \ldots, \theta^{m}\right)$, and the last $m+1$ through $k$ columns correspond to the labels for the weights in the simplex $\left(\theta^{m+1}, \ldots, \theta^{k}\right)$.

Given a vector $e=(1, \ldots, 1)$, the vector of interest is $\alpha=\left(\alpha_{1}, \ldots, \alpha_{k}\right)$, with $\alpha_{i} \geq 0, \forall i$, such that $A \alpha=e$. Scarf's algorithm makes use of the fact that if the set of non-negative solutions to $A \alpha=e$ is bounded, then there exists a subsimplex $\left(\theta^{j}, \ldots, \theta^{j+m}\right)$ such that the 
columns $j$ through $j+m$ of $A$ form a feasible basis for $A \alpha=e$. The idea is that a subsimplex of $m$ vectors can be chosen from $\left(\theta^{1}, \ldots, \theta^{k}\right)$, such that the vector $e$ is contained in the convex hull of their images.

The subsimplex which can be used to approximate a competitive equilibrium is reached through a series of linear programming pivot steps. The algorithm begins with a subsimplex made up of the vectors $\left(\theta^{2}, \ldots, \theta^{m}, \theta^{j}\right)$, and a feasible basis consisting of the labels $\left(L^{1}, \ldots, L^{m}\right)$. The label $L^{j}$ is brought into the feasible basis and a pivot step is performed on this new column. A unique column in the feasible basis is then eliminated. The corresponding vector in the subsimplex is removed and a new vector is introduced to the subsimplex. This process continues until either $L^{1}$ is removed from the feasible set or $\theta^{1}$ is introduced to the subsimplex, which implies that the columns of the subsimplex and the feasible basis coincide. The proof that a pivot step can always be carried out and the conditions under which the vector to be eliminated is unique are contained in chapter 4 (Scarf 1973), along with the proof that a subsimplex exists with labels that form a feasible basis.

Scarf's algorithm must converge to an approximate competitive equilibrium in a finite number of steps. This is due to the fact that the grid is finite and that the algorithm cannot cycle (Scarf (1973) pp. 45-48). One weakness of the algorithm is that the closeness of the approximation depends on the size of the grid, but the finer the grid, the slower the algorithm. However, there have been many advances in this area. Arrow and Kehoe (1992) contains a review of more efficient versions of Scarf's algorithm. I intend to make use of these in the future. 


\section{Examples}

This section contains several examples illustrating the richness of this environment. The first two examples show equilibrium school composition and individual consumption when there are two types of parents. One example results in complete segregation across schools, while the other has some integrated schools. This difference in student body composition is due to the different ways peer group effects can be interpreted in the schooling technology. In the last example the number of types of parents is increased from two to four. There are two income levels and two learning efficiency levels, yielding wealthy, efficient learners; wealthy, inefficient learners; poor, efficient learners; and poor, inefficient learners. In equilibrium there is a mixed school with the wealthy, inefficient learners subsidizing the poor, efficient learners to such an extent that the poor are paying nothing to attend the school.

\subsection{Functional Forms}

I choose the following functional form for utility:

$$
U^{i}(x)=\log (c)+\sum_{s} f_{s}^{i} \pi_{s}^{i}
$$

$f_{s}^{i}$ is the human capital of a type $i$ 's child who attends a type $s$ school. A type $i$ parent gets $f_{s}^{i}$ utility if the child attends school $s$.

The production function for human capital is a function of a type specific, learning efficiency parameter, the peer group, and per pupil expenditures. In all of the examples here, the peer group is measured as the average learning efficiency in a school, $\sum_{i} n_{s}^{i} a^{i}$. The functional form of the technology varies in the following examples. 


\subsection{Two Types}

Suppose we have two types of parents, poor and rich. Since there are only two types, the distribution of earnings is approximated by a two point distribution. Suppose that $80 \%$ of the population is poor and $20 \%$ of the population is rich. Taking data from the 1992 census on money earnings of full time workers in the United States, we see that if the earnings of the poor are normalized to 1 , the earnings of the rich must be 3.6. Therefore, $\lambda^{1}=.8$ and $\lambda^{2}=.2$, and $h^{1}=1$ and $h^{2}=3.6$. The learning efficiency parameter is assumed to be identical to the human capital parameter. So, $a^{1}=1$ and $a^{2}=3.6$. The next two examples illustrate the different outcomes that arise under different assumptions about how peer group effects enter the schooling technology.

\section{Example with Complete Segregation}

Henderson, Mieskowski, and Sauvageau (1973) find that peer group effects affect students of differing abilities in the same way. Here we incorporate that assumption into the schooling technology in the following manner:

$$
f_{s}^{i}=\left(a^{i}\right)^{\alpha}\left(\sum_{i} n_{s}^{i} a^{i}\right)^{\gamma}\left(e_{s}\right)^{\psi}, \forall i .
$$

The parameter $\psi$ is chosen to be .1, this follows Card and Krueger (1992). The other two parameters are chosen so that if everyone's learning efficiency parameter is scaled up by a constant, human capital outcomes increase by the same constant. Therefore, $\alpha+\gamma=1$. I choose $\gamma=.6$ and $\alpha=.4$. Lastly, the grid of possible school types is chosen so that there are over 300 school possibilities.

As you can see in Table 1, there are two schools operating in equilibrium. The first school is composed entirely of type 2 , the rich. The expenditures are .9 per student, and the price of attending is exactly .9. The human capital acquired by the students attending this 
Table 1: School Characteristics

\begin{tabular}{||l||c|c|c||}
\hline School (z) & Exp & Type 1 (p) & Type 2(p) \\
\hline $1(.2)$ & .9 & & $1(.9)$ \\
\hline $2(.8)$ & .1 & $1(.1)$ & \\
\hline
\end{tabular}

school is 3.56. The second school is made up entirely of type 1 , the poor. The per student expenditures are .1, and the price covers that at .1. The human capital acquired by these students is .79. Notice that since there is complete segregation, when these children grow up and become parents, there will still only be two types.

Table 2: Consumption Expenditures

\begin{tabular}{||l||c|c|}
\hline Expenditure & Type 1 & Type 2 \\
\hline Consumption & .9 & 2.7 \\
\hline
\end{tabular}

Table 2 show what equilibrium personal consumption is for the parents of each type. Rich parents are consuming more in absolute terms than the poor parents. However, the rich spend relatively more of their incomes on education than the poor parents.

\section{Example with some Integration}

The Coleman Report (1966) finds that although socioeconomically disadvantaged students benefit from an increase in the quality of their peer group, socioeconomically advantaged students perform well in any environment. To incorporate the hypothesis that the advantaged students aren't affected by their peer group, I introduce another human capital production 
function. Suppose children of type 1 parents still have technology,

$$
f_{s}^{1}=\left(a^{1}\right)^{\alpha}\left(\sum_{i} n_{s}^{i} a^{i}\right)^{\gamma}\left(e_{s}\right)^{\psi},
$$

while the children of type 2 parents have technology,

$$
f_{s}^{2}=\left(a^{2}\right)^{\alpha}\left(\sum_{i} n_{s}^{i} a^{2}\right)^{\gamma}\left(e_{s}\right)^{\psi}
$$

Instead of the peer group measure of average learning efficiency, children of type 2 parents always have a peer group measured by their higher learning efficiency. The parameters $\psi, \gamma$, and $\alpha$ are chosen as before. And the grid of possible school types is identical to the one above.

Table 3: School Characteristics

\begin{tabular}{||l||c|c|c||}
\hline School (z) & Exp & Type 1 (p) & Type 2(p) \\
\hline $1(.24)$ & .8 & $.3(.93)$ & $.7(.74)$ \\
\hline $2(.05)$ & .7 & $.3(.91)$ & $.7(.61)$ \\
\hline $3(.71)$ & .1 & $1(.1)$ & \\
\hline
\end{tabular}

As you can see in Table 3, there are now three schools operating in equilibrium. The first two are mixed schools and the last is a segregated school. The first two schools have .3 of type 1 students and .7 of type 2 students. They differ on expenditure levels, with the first school spending .8 per pupil, while the second school spends .7 per pupil. As you can see type 1 parents are subsidizing type 2 parents, to allow their children to benefit from the positive peer affect of type 2's higher learning efficiency. The human capital a type 1 student receives is 1.64 , from the first school, and 1.62 from the second school. A type 2 student acquires 3.10 from the first school, and 3.06 from the second school. The last school is composed entirely of type 1 students. The per student expenditures are .1 , and the price 
covers that at .1. The human capital acquired by these students is .79. As opposed to the case of complete segregation above, this example will give rise to a next generation with essentially three types of parents, $h^{1}=.79, h^{2}=1.64$, and $h^{3}=3.10$.

Table 4: Consumption Expenditures

\begin{tabular}{||l||c|c|}
\hline Expenditure & Type 1 & Type 2 \\
\hline Consumption & .81 & 2.88 \\
\hline
\end{tabular}

Table 4 shows what equilibrium personal consumption is for the parents of each type. Notice that the poor parents are spending more of their income on education here than in the previous example, while the rich, having schooling subsidized, spend relatively more on consumption.

\subsection{Four Types}

Now suppose there are four types of parents, those endowed with low human capital and low learning efficiency, those endowed with low human capital and high learning efficiency, those endowed with high human capital and low learning efficiency, and those endowed with high human capital and high learning efficiency. I will refer to these as types $1,2,3$, and 4 , respectively. I will continue to suppose that $80 \%$ of the population is poor and $20 \%$ of the population is rich. I assume that half of the poor and half of the rich are endowed with high learning efficiency. Therefore, $\lambda^{1}=.4, \lambda^{2}=.4, \lambda^{3}=.1$, and $\lambda^{4}=.1$. Human capital and learning efficiency endowments are as before, $h^{1}=1, h^{2}=1, h^{3}=3.6, h^{4}=3.6$, and $a^{1}=1, a^{2}=3.6, a^{3}=1, a^{4}=3.6$. 
The technology is the same for all types:

$$
f_{s}^{i}=\left(a^{i}\right)^{\alpha}\left(\sum_{i} n_{s}^{i} a^{i}\right)^{\gamma}\left(e_{s}\right)^{\psi}, \forall i
$$

And the parameters are as in the previous example, $\alpha=.4, \gamma=.6$, and $\psi=.1$. There are over 3000 possible school types.

Table 5: School Characteristics

\begin{tabular}{||l||c|c|c|c|c||}
\hline School $(\mathbf{z})$ & Exp & Type 1 $(\mathbf{p})$ & Type 2 $(\mathbf{p})$ & Type 3 $(\mathbf{p})$ & Type 4 $(\mathbf{p})$ \\
\hline $1(.1)$ & .9 & & & & $1(.9)$ \\
\hline $2(.5)$ & .3 & & $.8(0)$ & $.2(1.5)$ & \\
\hline $3(.4)$ & .1 & $1(.1)$ & & & \\
\hline
\end{tabular}

Table 5 contains the equilibrium schooling structure. Three schools are being operated. The first is composed entirely of the rich, efficient learners. Expenditures at that school are .9 , and the price reflects that. The human capital acquired by the children who attend this school is 3.56. The last school is composed entirely of the poor, inefficient learners. Per student expenditures and price are .1. The human capital acquired by these students is .79. The second school is a mixed school. It is composed of rich, low efficiency learners, and poor, high efficiency learners. The per student expenditures are .3. The rich, inefficient learners subsidize the poor, efficient learners to such an extent that the poor pay nothing to attend school. Their price is 0 , while the rich, inefficient learners pay 1.5. The human capital acquired by the efficient and inefficient learners is 2.91 and 1.74 , respectively.

Table 6 contains equilibrium consumption for all four types of parents. Recall that the first two types and the second two types have the same income level. However, type 2 consumes more than type 1 . This is because type 2 parents don't have to pay for schooling, 
Table 6: Consumption Expenditures

\begin{tabular}{||l||c|c|c|c||}
\hline Expenditure & Type 1 & Type 2 & Type 3 & Type 4 \\
\hline Consumption & .9 & 1.0 & 2.1 & 2.7 \\
\hline
\end{tabular}

therefore they spend their entire income on consumption. Type 4 parents consume more than type 3 parents, because type 3 parents are spending so much more on schooling subsidizing the poor, 1.5 as opposed to .9 .

\section{$5 \quad$ Policy Exercises}

In this section I take the example with four types of parents in the last section, and consider the effects a variety of policy changes have on welfare and the distribution of human capital. The purpose of performing these exercises is to illustrate how this environment can be used to answer policy questions, and to give a sense of what kinds of policy questions can be addressed in this environment. I do not make policy prescriptions, on the basis of these exercises, at this time. In future work, I plan to increase the number of types of parents and calibrate the model. This will allow for a more serious study of education policy.

I make use of the fact that in this environment, I can constrain the set of possible school types without adjusting the computational method. This means that a school's per student expenditure levels can be limited or fixed, and various restrictions can be placed on a school's student body composition. The first two exercises consider second best outcomes, by restricting the set of possible schools. The third exercise involves a redistribution of income through a voucher policy. In that case, the set of possible school types isn't restricted, but the parents are restricted to spending the voucher on education. This is a bit more 
complicated computationally.

To reduce inequality, it has been suggested that per student expenditures be equalized across schools. In the first exercise, I do just that. I suppose all schools must spend the same amount per pupil. Given that parents have single peaked preferences, the expenditure level preferred by the median voter is the one which would win by majority vote. I restrict the set of possible schools to those with this level of spending, and I then find the resulting competitive equilibrium. I compare the second best outcome with the efficient case in Section 4. There is obviously a welfare loss, but there is also a reduction in both the range and the standard deviation of next period's human capital distribution. Here, welfare is measured as the weighted sum of utilities, where the weights are those that yield a pareto optimal allocation that can be supported as a competitive equilibrium with no transfers.

If peer effects are important, then student body composition is another instrument which can be used to equalize outcomes. In the second exercise, if the rich inefficient learners mix with the poor efficient learners, I force them to also mix with some poor inefficient learners. This allows some of the poor inefficient learners to benefit from a better quality peer group. I continue to constrain expenditures, but now the level of expenditures preferred by the median voter falls. I compare the second best results to the first best case of Section 4. Once again there is an efficiency loss, but now due to the reduction in per student expenditures, there is also a loss in the average human capital acquired. Gains are made in the reduction of both the range and the standard deviation of next period's human capital distribution.

The last exercise investigates the consequences of a voucher system on welfare and inequality. The income of the parent is taxed proportionally, and the revenues are returned in the form of a lump sum educational voucher. It becomes a transfer from the rich to the poor, which must be spent on education. 
Table 7: Comparisons to Efficiency

\begin{tabular}{||l||c|c|c|c||}
\hline Case & Welfare & Mean h & Std h & Range h \\
\hline Efficient & 1.1705 & 2.01 & 1.139 & 2.77 \\
\hline Constrained Expenditures & .9933 & 2.01 & 1.039 & 2.30 \\
\hline Forced Integration & .9929 & 1.93 & .955 & 2.21 \\
\hline
\end{tabular}

\subsection{Constraining School Expenditures}

Several states are trying to equalize per student expenditures across districts. Many expect that by equalizing expenditures, human capital outcomes will be more equal. In this exercise I evaluate the implications of such a policy on efficiency and on next period's distribution of human capital, when the peer group matters. Suppose that all schools are required to spend the same amount per student. In this environment that entails restricting the possible schools to those with a certain level of expenditures. I continue to allow for all kinds of mixing across individual types.

Table 8: School Characteristics

\begin{tabular}{||l||c|c|c|c|c||}
\hline School $(\mathbf{z})$ & Exp & Type 1 $(\mathbf{p})$ & Type 2 $(\mathbf{p})$ & Type 3 $(\mathbf{p})$ & Type 4 (p) \\
\hline $1(.1)$ & .3 & & & & $1(.3)$ \\
\hline $2(.5)$ & .3 & & $.8(0)$ & $.2(1.5)$ & \\
\hline $3(.4)$ & .3 & $1(.3)$ & & & \\
\hline
\end{tabular}

The expenditure level that is chosen is the one that would win in majority voting. Since preferences are single peaked, the expenditure level preferred by the poor efficient learners wins. This expenditure level is .3. The equilibrium schooling structure is shown in 
Table 8. The mixing across schools is identical to that under efficiency, however expenditures are all constrained to .3 . Once again the rich inefficient learners are subsidizing the poor efficient learners, this is reflected in their respective prices of 1.5 and 0 . The two segregated schools are charging .3, which reflects the expenditure constraint.

Table 9: Next Period's Human Capital

\begin{tabular}{||c||c||}
\hline Human Capital Accumulated & Fraction of Individuals \\
\hline 3.19 & .1 \\
\hline 2.91 & .4 \\
\hline 1.74 & .1 \\
\hline .89 & .4 \\
\hline
\end{tabular}

Table 9 shows next period's distribution of human capital. Recall that under efficiency the children of the rich efficient learners acquire 3.56 units of human capital, and the children of the poor inefficient learners acquire .79 units of human capital. Those attending the mixed school accumulate the same amount of human capital under efficiency as under this policy, since in both cases the expenditure level is .3. Therefore, the distribution of human capital under this policy has a smaller range.

Table 7 contains a comparison of this policy, of constraining expenditures across schools, with efficiency. The efficiency loss is $15 \%$, but the range of the distribution of human capital is reduced $17 \%$ and the standard deviation is reduced by almost $9 \%$. There is a trade off between efficiency and equality. The question then is, does this policy accomplish it's proponents goals? If the peer group matters, restricting expenditures is only one part of equalizing outcomes. Obviously, social policy can do nothing to affect innate ability or learning efficiency, but it can be used to engineer peer groups. So the more important 
the peer group is, relative to expenditures, in human capital accumulation, the less simply constraining expenditures will help equalize future incomes.

\subsection{Forced Integration}

In this exercise I use the peer group as an instrument to equalize educational outcomes, or human capital accumulation. This is done by forcing certain types of mixing within schools. If a school is admitting a mix of rich inefficient learners and poor efficient learners, as in the previous example, they must now admit some poor inefficient learners. This forces the rich inefficient to not only subsidize the poor efficient learners, but the poor inefficient learners as well. The expenditure level preferred by the median voter is now .2 .

Table 10: School Characteristics

\begin{tabular}{||l||c|c|c|c|c||}
\hline School $(\mathbf{z})$ & Exp & Type 1 $(\mathbf{p})$ & Type 2 $(\mathbf{p})$ & Type 3 $(\mathbf{p})$ & Type 4 (p) \\
\hline $1(.1)$ & .2 & & & & $1(.2)$ \\
\hline $2(.2)$ & .2 & & $1(.2)$ & & \\
\hline $3(.33)$ & .2 & $.1(.69)$ & $.6(-.43)$ & $.3(1.30)$ & \\
\hline $4(.37)$ & .2 & $1(.2)$ & & & \\
\hline
\end{tabular}

The equilibrium here is displayed in Table 10. There is a completely segregated school that all of the rich efficient learners attend, and another with $92 \%$ of the poor inefficient learners. The mixed school now includes the remaining $8 \%$ of the poor inefficient students, due to the new policy. At this school, which contains $40 \%$ inefficient learners and $60 \%$ efficient learners, the rich inefficient learners are subsidizing both types, paying 1.3. The sense in which the rich inefficient learners are subsidizing the poor inefficient learners is that the poor inefficient learners wouldn't be willing to, on their own, pay the amount required 
by the poor efficient learners to mix. Here the rich inefficient learners are subsidizing the poor inefficient learners by helping them subsidize the poor efficient learners. The poor inefficient learners pay .69 to attend the school, which is still higher than the .3 per student expenditures, but much lower than the 1.3 that the rich inefficient learners pay. The poor efficient learners actually get paid -.43 to attend this school. Recall that under efficiency the mixed school was free for the efficient learners, here it must be even cheaper because the average learning efficiency of the peer group is lower, and so are the expenditures. Lastly, there is a school which contains only the poor efficient learners. This school arises because the poor efficient learners are not only getting worse outcomes in the mixed school, but they now have some extra money from their stipend that they can spend on a segregated school.

Table 11: Next Period's Human Capital

\begin{tabular}{||c||c||}
\hline Human Capital Accumulated & Fraction of Individuals \\
\hline 3.06 & .3 \\
\hline 2.50 & .2 \\
\hline 1.50 & .13 \\
\hline .85 & .37 \\
\hline
\end{tabular}

The distribution of human capital is shown in Table 11. Because the expenditure level is only .2 , there is a reduction in the human capital acquired at most levels, as compared to efficiency. However, there are more people in the highest category and fewer in the lowest. From Table 7, notice the spread between the highest and lowest levels of human capital is $20 \%$ smaller under a forced integration policy. The standard deviation of the distribution is $20 \%$ less here than under efficiency. But there is a trade off. The average human capital acquired falls $4 \%$, and there is an efficiency loss of $15 \%$. 


\subsection{Voucher System}

Several states have implemented or are considering implementing educational voucher systems. Depending upon the specific plan, those who qualify receive a voucher which can be applied towards educational expenditures. In this exercise, there is a proportional tax on the parent's income which is refunded to the parent in the form of a lump sum voucher. Parents are constrained to spend the voucher on their children's education.

Table 12: School Characteristics

\begin{tabular}{||l||c|c|c|c|c||}
\hline School (z) & Exp & Type 1 (p) & Type 2 $(\mathbf{p})$ & Type 3 (p) & Type 4 (p) \\
\hline $1(.1)$ & .9 & & & & $1(.9)$ \\
\hline $2(.18)$ & .3 & & $.5(-.75)$ & $.5(1.35)$ & \\
\hline $3(.1)$ & .4 & & $.9(.20)$ & $.1(2.20)$ & \\
\hline $4(.22)$ & .5 & & $1(.5)$ & & \\
\hline $5(.4)$ & .2 & $1(.2)$ & & & \\
\hline
\end{tabular}

The proportional tax is $10 \%$ which corresponds to a voucher of size .152 . Returning to the four type example of Section 4, notice that both types of poor choose to spend less than this amount before the voucher system. Table 12 contains the competitive equilibrium schooling structure under this voucher policy. The rich, efficient learners are not affected by the change in so far as schooling. Obviously, their income falls under the voucher policy, but this only affects consumption. The poor, inefficient learners still attend a segregated school, but this school has a higher per pupil expenditure level than previously. This increase reflects the voucher.

There are two mixed schools where the rich, inefficient learners subsidize the poor, efficient learners. Expenditures are .3 and .4 , and the percent of efficient learners is .5 and 
.9 , in these two schools, respectively. The first mixed school has a pricing structure such that the poor are being paid .75 to attend, while the rich pay 1.35. The second mixed school is of higher quality than the first, hence the poor pay .2 and the rich pay 2.2 . Because the poor efficient learners are receiving the voucher now, they have the funds to form a segregated school with higher per student expenditures of .5 .

Basically the voucher takes consumption away from the rich and transfers it to the poor in the form of educational expenditures. There is a slight affect on the educational expenditures of the rich inefficient learners. Their expenditures fall from 1.5 to 1.4. As noted previously the rich efficient learners spend the same amount on education as they did before the voucher system was implemented. And now, post voucher system, both types of poor are spending more on education. Under a voucher policy, total educational expenditures rise from .28 to .374 .

Table 13: Next Period's Human Capital

\begin{tabular}{||c||c||}
\hline Human Capital Accumulated & Fraction of Individuals \\
\hline 3.56 & .1 \\
\hline 3.36 & .22 \\
\hline 3.14 & .09 \\
\hline 2.44 & .09 \\
\hline 1.88 & .01 \\
\hline 1.46 & .09 \\
\hline .85 & .4 \\
\hline
\end{tabular}

Table 13 contains the resulting distribution of human capital and Table 14 contains welfare and some measures of the distribution of human capital under the voucher system. 
Table 14: Welfare and Human Capital Distribution Measures

\begin{tabular}{||l||c|c|c|c||}
\hline Case & Welfare & Mean $\mathbf{h}$ & Std $\mathbf{h}$ & Range $\mathbf{~}$ \\
\hline Voucher & 1.3490 & 2.09 & 1.160 & 2.71 \\
\hline
\end{tabular}

The standard deviation rises, while the range falls, as compared to the case of no voucher system. The average human capital acquired under the voucher system is higher. There is a rather large gain in welfare, a $15 \%$ increase. Because this change is sensitive to the specification of the utility function, I hesitate to place much value on this outcome at this stage. As mentioned previously, I plan to increase the number of types and calibrate the model.

\section{Conclusion}

In this paper I develop a framework for applied general equilibrium analysis when there are peer effects. The techniques are illustrated in the context of schooling, where peer effects are viewed as important. I analyze school formation and composition, when a student's educational achievement depends upon the school's peer group and educational expenditures, and the student's type. I find that, depending upon the specification of the technology which converts these inputs into educational achievement, a variety of outcomes can arise in equilibrium. For example there can be segregation or mixing across schools, or a combination of both in equilibrium. Lastly, I consider the welfare and distributional effects of three policy changes. I show that equalizing expenditures across schools reduces the range and standard deviation of the distribution of human capital, as does forcing certain forms of integration. Both policies imply a welfare loss. The last exercise investigates a voucher system, which 
given the specification of the utility function, is welfare improving.

Finding an equilibrium in this environment is a difficult problem. Standard computational methods, such as Newton, are not always successful, because the Negishi mapping from the weights on individual types to transfers is a correspondence. This correspondence arises from the linearity of the utility function over schooling. Therefore, at times, a more general search algorithm, one which can deal with correspondences, is needed. The method employed here is based on Scarf (1973).

In future work, I plan to use the techniques developed in this paper to further explore the welfare and distributional ramifications of alternative methods of educational finance and policy, when there are peer group effects. I intend to calibrate a model, with more than just four types, to allow for such policy comparisons. I will also consider more policy exercises. Aside from extensions of those contained in Section 5, I would like to see what happens when learning efficiency is private information. The computational methodology developed here can be modified to determine not only the welfare implications of such policies, but also their affects on student body composition and per student expenditure, and hence educational outcomes and future income, when there are peer effects. 


\section{References}

[1] Arrow, Kenneth J. and Timothy J. Kehoe. "Distinguished Fellow Herbert Scarf's Contributions to Economics." Journal of Economic Perspectives. 8 (1994): 161-181.

[2] de Bartolome, Charles A. M. "Equilibrium and Inefficiency in a Community Model with Peer Group Effects." Journal of Political Economy. 98 (1990): 110-133.

[3] Benabou, Roland. "Heterogeneity, Stratification, and Growth: Macroeconomic Implications of Community Structure and School Finance." American Economic Review. 86 (1996): 584-609.

[4] Card, David and Alan Krueger. "Does School Quality Matter? Returns to Education and the Characteristics of Public Schools in the United States." Journal of Political Economy. 100 (1992): 1-40.

[5] Cole, Harold L. and Edward C. Prescott. "Valuation Equilibria with Clubs." Federal Reserve Bank of Minneapolis, Working Paper 524. March 1996.

[6] Coleman, James S., Ernest Q. Campbell, Carol J. Hobson, James McPartland, Alexander M. Mood, Frederic D. Weinfeld, and Robert L. York. Equality of Educational Opportunity. Washington: U.S. Department of Health, Education, and Welfare, National Center Educational Statistics, 1966.

[7] Epple, Dennis and Richard E. Romano. "Competition between Private and Public Schools, Vouchers and Peer Group Effects." Manuscript. University of Florida, 1993.

[8] Henderson, J. Vernon, Peter Mieskowski, and Yvon Sauvageau. "Peer Group Effects and Educational Production Functions." Journal of Public Economics. 10 (August 1978): 97-106. 
[9] McKenzie, Lionel W. "On the Existence of General Equilibrium for a Competitive Market." Econometrica. 27 (1959).

[10] Rogerson, Richard. "Indivisible Labor, Lotteries and Equilibrium." Journal of Monetary Economics. 21 (1988): 3-16.

[11] Scarf, Herbert. The Computation of Economic Equilibria. Cowles Foundation Monograph 24, 1973.

[12] Stokey, Nancy L and Robert E. Lucas with Edward C. Prescott.

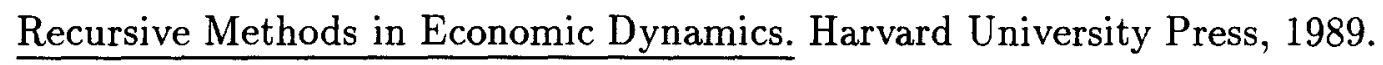

[13] Summers, A. and B. Wolfe. "Do Schools Make a Difference?" American Economic Review. 67 (1977): 639-652. 


\section{A The Modified Mas-Colell Mapping}

\section{Finding a pareto optimal allocation}

Here I discuss the methodology used to find a pareto optimal allocation, $\left(\hat{c}\left(u_{h}\right), \hat{z}\left(u_{h}\right)\right)$, given a vector of utilities over schooling, $u_{h}$. This vector is relative, in the sense that all scaled versions of $u_{h}$ give rise to the same pareto allocation. Each scaled $u_{h}$ vector yields a schooling and consumption allocation that satisfies optimality conditions. However, only one of these allocations also satisfies feasibility. Given a $u_{h}$ vector, the process begins by choosing an initial scalar $\alpha$. The corresponding optimal consumption and schooling structure is then constructed. If the allocation is infeasible, then the utility vector is scaled down by decreasing $\alpha$, if not all resources are being used, then the utility vector is scaled up by increasing $\alpha$. Given $u_{h}$, there is a unique $\alpha$ which yields a pareto optimal allocation. This is shown in proposition 12 .

The first step in constructing the allocation, given $\alpha$, entails finding the pareto optimal schooling structure. This is done by solving the following problem:

$$
\begin{array}{ll}
\min _{z} & \sum_{s} z_{s} e_{s} \\
\text { s.t. } & \lambda^{i} \sum_{s} \frac{z_{s} n_{s}^{i}}{\lambda^{i}} v_{s}^{i} \geq \alpha u_{h}^{i}, \quad i=1, \ldots, I, \\
& \sum_{s} z_{s} n_{s}^{i}=\lambda^{i}, \quad i=1, \ldots, I \\
\text { where } & v_{s}^{i}=v_{s}^{i}\left(f_{s}^{i}\left(n_{s}^{1}, \ldots, n_{s}^{I}, e_{s}\right)\right) .
\end{array}
$$

Total expenditures over schooling are minimized subject to $2 I$ constraints. The first $I$ constraints are utility constraints, while the last $I$ constraints are attendance constraints. The attendance constraints formalize the assumption that every child must attend some school. The solution to this problem yields the optimal schooling structure, $z(\alpha)$, and a set of $2 I$ lagrange multipliers, or dual solutions, $\mu_{h}^{i}(\alpha), i=1, \ldots, I$. 
Proposition 9 There exists a solution to $(6), z(\alpha)$.

Proof: The Theorem of the Maximum is used to establish an optimum exists. First, the constraint set is closed and bounded. Second, the objective function is continuous. And third, the $v_{s}^{i}$ are chosen so that for some $s, v_{s}^{i}=0$, and for some $s, v_{s}^{i}$ is very large, therefore the constraint set is nonempty.

$\diamond$

Proposition 10 The solution, $z(\alpha)$, to the expenditure minimization problem (6), is an optimal allocation of resources over schooling, given $\alpha$.

Proof: Expenditure minimization implies utility maximization, which in turn implies optimality.

$\diamond$

To find the vector of individual consumption, $c(\alpha)$, which corresponds to the optimal schooling allocation, $z(\alpha)$, consider the following problem:

$$
\begin{array}{ll}
\min _{c} & \sum_{i} \lambda^{i} c^{i} \\
\text { s.t. } & \lambda^{i} u\left(c^{i}\right) \geq u_{c}^{i} \quad i=1, \ldots, I .
\end{array}
$$

Notice the lagrange multipliers on the $I$ constraints of this problem are, $\mu_{c}^{i}=\frac{1}{u^{\prime}\left(c^{i}\right)}, i=1, \ldots, I$. Pareto optimality requires that the first $I$ lagrange multipliers in problem (6) are equivalent to the lagrange multipliers in problem (7). Recall, the dual solution of problem (6), is known. Therefore, optimal consumption, $(\alpha)$, can be constructed from, $\mu_{h}^{i}(\alpha)=\frac{1}{u^{\prime}\left(c^{i}\right)}, i=1, \ldots, I$.

Proposition 11 If $(c(\alpha), z(\alpha))$ is a pareto optimal allocation, then $\mu_{h}^{i}(\alpha)=\frac{1}{u^{\prime}\left(c^{i}\right)}, i=1, \ldots, I$, where $\mu_{h}^{i}(\alpha), i=1, \ldots, I$, are the dual solutions of problem (6). 
Proof: $\mu_{h}^{i}$ is the marginal resource cost of $u_{h}^{i}$, and $\mu_{c}^{i}$ is the marginal resource cost of $u_{c}^{i}$. If $\mu_{h}^{i} \neq \mu_{c}^{i}$ resources can be rearranged to make person $i$ better off, hence the allocation wasn't pareto optimal.

Given $z(\alpha)$ and $c(\alpha)$, feas $(\alpha)=\sum_{i} \lambda^{i} h^{i}-\sum_{i} \lambda^{i} c^{i}(\alpha)-\sum_{s} z_{s}(\alpha) e_{s}$, is calculated. If feas $<0$ (feas $>0$ ), then $\alpha$ is decreased (increased), and the process of finding the optimal allocation is repeated. The procedure continues until, feas $=0$. Once feasibility holds, the corresponding consumption and schooling allocation, $\hat{z}\left(u_{h}\right)$ and $\hat{c}\left(u_{h}\right)$, is pareto optimal.

Proposition 12 For each $u_{h}$ vector, there exists a unique scalar, $\hat{\alpha}$, which corresponds to a pareto optimal allocation.

Proof: First I show that total feasible consumption as a function of $\alpha, C^{f}(\alpha)$ is decreasing. I then establish that the optimal total consumption as a function of $\alpha, C^{\circ}(\alpha)$ is weakly increasing. Therefore, there is only one $\alpha$, where total consumption is optimal and feasible.

Let $S(\alpha)$ be the solution to (6). $S(\alpha)$ is increasing in $\alpha$. Total resources $H=\sum_{i} \lambda^{i} h^{i}$, is constant over $\alpha$. Therefore, total feasible consumption, $C^{f}(\alpha)$ is decreasing in $\alpha$.

Notice that the first $I$ lagrange multipliers, or dual solutions to problem (6), are the marginal resource costs of $u_{h}$, while $S(\alpha)$ is the total resource cost of $u_{h}$. Hence we have:

$$
S(\alpha)=\sum_{i} \int_{0}^{\alpha} \mu_{h}^{i}(t) d t
$$

If $u\left(c^{i}\right)=\log \left(c^{i}\right)$, then optimality implies $\mu_{h}^{i}(\alpha)=c^{i}(\alpha)$. So:

$$
S(\alpha)=\sum_{i} \int_{0}^{\alpha} c^{i}(t) d t
$$

Since $c^{i}(\alpha)$ is continuous, the integration and the summation can be interchanged. Therefore, the following relationship between $S(\alpha)$ and total optimal consumption $C^{\circ}(\alpha)$ is established:

$$
S(\alpha)=\int_{0}^{\alpha} C^{o}(t) d t .
$$


The Fundamental Theorem of Calculus implies:

$$
S^{\prime}(\alpha)=C^{\circ}(\alpha)
$$

So:

$$
S^{\prime \prime}(\alpha)=C^{o^{\prime}}(\alpha)
$$

Since $S(\alpha)$ is convex, $S^{\prime \prime}(\alpha) \geq 0$. Therefore, $C^{o}(\alpha)$ is weakly increasing.

Because the optimal total consumption $C^{\circ}(\alpha)$ is weakly increasing, and the feasible total consumption $C^{f}(\alpha)$ is decreasing, there is a unique $\alpha$ which corresponds to a pareto optimal allocation.

\section{Finding the transfers}

In order to find the transfers which support a pareto optimal allocation as a competitive equilibrium, a price system is needed. The Second Welfare Theorem, which ensures the existence of a price system which supports each $u_{s c}$-pareto optimal allocation as a competitive equilibrium with transfers, has been shown to hold. Therefore, such a price system exists.

Proposition 13 Given the solution to the $u_{h}$-pareto problem, $\left\{z\left(u_{h}\right), c\left(u_{h}\right)\right\}$, price system,

$$
p_{s}^{i}\left(u_{h}\right)=\mu_{h}^{i}\left(u_{h}\right) v_{s}^{i}+\mu_{h}^{i+I}\left(u_{h}\right), \quad \forall i, s
$$

supports $\left\{z_{s}\left(u_{h}\right), x_{c}\left(u_{h}\right)\right\}$ as a quasi-competitive equilibrium, where the $\mu_{h}^{i}$ 's are the lagrange multipliers from the $u_{h}$-pareto problem. 


\section{Proof}

I construct a price system from the non-positive profit condition of each school, and the first order condition, from the expenditure minimization problem, for each school. Returning to problem (6), notice that if a school is operated $\left(z_{s}\left(u_{h}\right)>0\right)$, then,

$$
e_{s}-\sum_{i=1}^{I} \mu_{h}^{i}\left(u_{h}\right) n_{s}^{i} v_{s}^{i}-\sum_{i=1}^{I} \mu_{h}^{i+I}\left(u_{h}\right) n_{s}^{i}=0
$$

Note, for all $s$, with $z_{s}\left(u_{h}\right)>0$, zero profits implies,

$$
e_{s}=\sum_{i} n_{s}^{i} p_{s}^{i}\left(u_{h}\right)
$$

Therefore:

$$
\sum_{i} n_{s}^{i}\left[p_{s}^{i}\left(u_{h}\right)-\mu_{h}^{i}\left(u_{h}\right) v_{s}^{i}-\mu_{h}^{i+I}\left(u_{h}\right)\right]=0, \forall s z_{s}\left(u_{h}\right)>0 .
$$

So a candidate price system is,

$$
p_{s}^{i}\left(u_{h}\right)=\mu_{s}^{i}\left(u_{h}\right) v_{s}^{i}+\mu_{h}^{i+I}\left(u_{h}\right), \quad \forall i, s z_{s}\left(u_{h}\right)>0 .
$$

Turning to those schools which are not operated $\left(z_{s}\left(u_{h}\right)=0\right)$, the first order condition from problem (6) is,

$$
e_{s}-\sum_{i=1}^{I} \mu_{h}^{i}\left(u_{h}\right) n_{s}^{i} v_{s}^{i}-\sum_{i=1}^{I} \mu_{h}^{i+I}\left(u_{h}\right) n_{s}^{i}>0 .
$$

If $z_{s}\left(u_{h}\right)=0$, profits of school $s$ are negative, so,

$$
e_{s}>\sum_{i} n_{s}^{i} p_{s}^{i}\left(u_{h}\right)
$$

Therefore:

$$
e_{s}>\sum_{i=1}^{I} \mu_{h}^{i}\left(u_{h}\right) n_{s}^{i} v_{s}^{i}+\sum_{i=1}^{I} \mu_{h}^{i+I}\left(u_{h}\right) n_{s}^{i}, \text { and } e_{s}>\sum_{i} n_{s}^{i} p_{s}^{i}\left(u_{h}\right), \forall s z_{s}\left(u_{h}\right)=0 .
$$

So a candidate price system is,

$$
p_{s}^{i}\left(u_{h}\right)=\mu_{h}^{i}\left(u_{h}\right) v_{s}^{i}+\mu_{h}^{i+I}\left(u_{h}\right), \quad \forall i, s z_{s}\left(u_{h}\right)=0
$$

which has the same structure as the price system for operating schools. 
The next proposition establishes the price system as one which supports each $u_{h}$-pareto optimal allocation as not only a quasi-competitive equilibrium with transfers, but as a competitive equilibrium with transfers.

Proposition 14 if for each person there is a point cheaper than the pareto optimal allocation, in their consumption possibility set, then the price system $p$, supports each $u_{h}$-pareto optimal allocation as a competitive equilibrium with transfers (Remark)

\section{Proof}

This follows from the fact that everyone will always be consuming positive amounts $c>0$, so that $c=0$ will be cheaper, holding $z_{s}$ fixed.

$\diamond$

Prices are easily constructed from the solution to problem (6). Transfers are then,

$$
t^{i}\left(u_{h}\right)=h^{i}-c^{i}\left(u_{h}\right)-\sum_{s} p_{s}^{i}\left(u_{h}\right) \frac{z_{s}\left(u_{h}\right) n_{s}^{i}}{\lambda^{i}}, i=1, \ldots, I .
$$

